\title{
The Mitigators of Ad Irritation and Avoidance of YouTube Skippable In-Stream Ads: An Empirical Study in Taiwan
}

\author{
Hota Chia-Sheng Lin ${ }^{1}$, Neil Chueh-An Lee ${ }^{2, *}$ and Yi-Chieh $\mathrm{Lu}^{2}$ \\ 1 Department of Leisure and Recreation Administration, Ming Chuan University, 5 De Ming Rd., \\ Gui Shan District, Taoyuan City 333, Taiwan; hotalin@mail.mcu.edu.tw \\ 2 Department of Marketing and Tourism Management, National Chiayi University, No. 580 Sinmin Rd., \\ Chiayi City 60054, Taiwan; luyechieh15@gmail.com \\ * Correspondence: neil_lee@mtm.ncyu.edu.tw
}

check for updates

Citation: Lin, H.C.-S.; Lee, N.C.-A.; Lu, Y.-C. The Mitigators of Ad Irritation and Avoidance of YouTube Skippable In-Stream Ads: An Empirical Study in Taiwan. Information 2021, 12, 373. https:// doi.org/10.3390/info12090373

Academic Editor: Vincenzo Moscato

Received: 7 August 2021

Accepted: 7 September 2021

Published: 14 September 2021

Publisher's Note: MDPI stays neutral with regard to jurisdictional claims in published maps and institutional affiliations.

Copyright: (c) 2021 by the authors. Licensee MDPI, Basel, Switzerland. This article is an open access article distributed under the terms and conditions of the Creative Commons Attribution (CC BY) license (https:// creativecommons.org/licenses/by/ $4.0 /)$.

\begin{abstract}
On YouTube, skippable in-stream advertisements (ads) are critical income for both YouTube and content creators. However, ads inevitably irritate viewers, and as a result, they tend to avoid ads. Thus, this study attempts to identify potential mitigators-source attractiveness and reciprocal altruism - of ad irritation and avoidance in the context of YouTube skippable in-stream ads. Using an online survey $(n=512)$ in Taiwan, the proposed model is examined by a partial least squares structural equation modeling analysis. The findings show that while ad irritation has a positive effect on ad avoidance, reciprocal altruism can significantly reduce both ad irritation and avoidance. However, source attractiveness fails to mitigate ad irritation and avoidance. Theoretical and managerial implications of these findings are discussed, and several solutions for reducing ad irritation and avoidance are provided.
\end{abstract}

Keywords: ad irritation; ad avoidance; reciprocal altruism; source attractiveness; skippable instream ad

\section{Introduction}

Recently, YouTube is the most popular video website worldwide [1]. About $88 \%$ of Internet users have a YouTube account [2], and more than 2.3 billion logged-in viewers visit YouTube each month [3]. Thus, YouTube has become an important platform for users to access information and publish original videos. On YouTube, users can be creators (also known as YouTubers), who regularly upload original videos to their personal channels. In 2020, the number of channels with one million subscribers increased by more than $65 \%$, and there were over 37 million YouTube channels [4]. By accessing YouTube videos, viewers can increase their knowledge or take a short break. They often subscribe to their favorite channels in order to receive the latest videos. Such interactions between creators and viewers on YouTube channels have created a huge online watching and advertising ecosystem.

On YouTube, advertising profit sharing is one of the indispensable revenues for creators. Creators, in order to keep their continuous creations, rely on in-stream advertisements (abbreviated as "ads") provided by YouTube to make income and profits. Although YouTube has launched several options for viewers to become paid members to avoid instream ads [5], most viewers tend to watch videos for free. Thus, in most situations, viewers must spend a little time watching skippable ads before or during watching videos [5]. Viewers are often irritated because they perceive anxiety and goal impediments from watching and waiting for such commercial slots to end, which in turn facilitate ad avoidance [6,7]. Researchers have also found that viewers who are forced to watch in-stream ads tend to click the skip-ad button $[8,9]$, resulting in ad ineffectiveness and reductions in creators' income and profits. Thus, how to increase viewers' motivation for watching in-stream ads and reduce their ad irritation and avoidance remains a critical issue. 
Although viewers often regard ads as irritating and tend to avoid them [10,11], we still find that some viewers who subscribe to channels are more willing to wait for ads to end. As we mentioned above, creators can get shared profits when viewers "watch ads" instead of "watching creator videos." Thus, some viewers, in order to support creators to continue to update their YouTube channels, may be delighted to watch in-stream ads on channels that they really like. This implies that there may be two possible mechanisms that viewers may reduce their ad irritation and ad avoidance. The first mechanism is source attractiveness. That is, viewers are attracted to their favorite creators and channels and may turn their affection for and devotion to the creators and channels into ad-watching motivation. This is what prior studies called celebrity endorsements [12]. That is, one person, who identifies with a celebrity, will change attitudes about and preferences to a product and even generate purchasing behavior in favor of that product [12]. Thus, such an endorsement effect may reduce both ad irritation and ad avoidance, improving ad effectiveness [13]. The second mechanism is altruism [14]. Viewers may consider watching in-stream ads as a type of altruistic behavior. That is, viewers support their favorite creators and channels by watching ads because they believe a decline in ad profit sharing may cause creators to be unable to make higher-quality videos. Consequently, altruism is likely to motivate viewers to watch in-stream ads, reducing ad avoidance behavior.

Accordingly, this study aims to investigate viewers' motivation for watching in-stream ads to reduce ad irritation and avoidance on their favorite YouTube channels, based on the source-attractiveness theory and the perspective of reciprocal altruism. Although prior studies have demonstrated that ad skepticism, irrelevance, prior negative experience, intrusiveness, psychological reactance, and so on are key antecedents of ad avoidance in various research contexts [10,15-18], no studies have drawn upon the aspects of source attractiveness and reciprocal altruism to study the said issue. Specifically, our research question is: What and how can increase viewers' motivation for watching in-stream ads and reduce their ad irritation and avoidance? Thus, the objective of this study is to develop a research model to explain how source attractiveness and reciprocal altruism may reduce YouTube viewers' ad irritation and ad avoidance. It is well known that the effectiveness of in-stream ads relies on the willingness of viewers to watch ads [19]. When viewers' ad-watching behaviors are voluntary and self-motivated, they will be more impressed by the ads, in turn increasing ad effectiveness. Thus, our research findings will contribute to advertising studies and help YouTube creators increase their ad effectiveness by showing them how to drive their viewers to watch in-stream ads.

The remainder of the paper is organized as follows. In the next section, we review the literature and develop a framework that outlines why we believe source attractiveness and reciprocal altruism are the key to reduce viewers' ad irritation and ad avoidance. Then, we detail our survey method. This is followed by our findings and discussion. Finally, we conclude this paper.

\section{Background and Research Framework}

In this section, we will review the literature about in-stream ads, ad avoidance, ad irritation, source attractiveness, and reciprocal altruism. We also develop hypotheses and a research model that outlines how source attractiveness and reciprocal altruism are the key to reduce viewers' ad irritation and ad avoidance.

\subsection{In-Stream Ads}

In general, there are six types of ads that creators can turn on to earn advertising profits. Three types of ads, including display ads, overlay ads, and sponsored cards, do not interfere with the content that viewers watch. Other types of ads, including skippable video ads, non-skippable video ads, and bumper ads, appear before, during, or after main videos. YouTube has found that placing ads before videos is most effective, but it is irritating for viewers [20]. Thus, YouTube launched skippable in-stream ads in 2010, which allowed viewers to skip ads after $5 \mathrm{~s}$ to improve ad effectiveness. Skippable in-stream ads are 
relatively acceptable for YouTube viewers because they have choices as to whether to skip ads [19]. In general, enabling more views on skippable in-stream ads, which is the most important income for content creators, can increase creators' potential ad revenue [21]. Thus, this study focuses on how to reduce ad irritation and the avoidance of skippable in-stream ads on YouTube.

\subsection{Ad Avoidance}

Ad avoidance, defined as "all actions by media viewers that differentially reduce their exposure to ad content" [16], is one of the major obstacles for advertisers [22]. In this study, ad avoidance refers to cognitive, affective, and behavioral resistance to skippable in-stream ads [6]. Cognitive resistance is a psychological defense mechanism that involves preventing mentally or emotionally upsetting content [6]. It is characterized as turning a viewer's attention away as soon as an in-stream ad begins. That is, a viewer can divert his or her attention from an in-stream ad. Affective resistance involves viewers' negative emotions that are negative attitudes toward ads [6,7]. Behavioral resistance is when viewers engage avoidance behaviors such as clicking a skip-ad button and scrolling down from the page [23].

Prior studies have demonstrated various antecedents of ad avoidance. Cho and Choeon [6] argue that perceived goal impediments, perceived ad clutters, and prior negative experiences can lead people to avoid ads on the Internet. Ad avoidance is a big challenge for advertisers [7]. Ad skepticism, irrelevance, and intrusiveness are also demonstrated as key drivers of viewers' ad avoidance [10,15-18]. Ad avoidance can further be explained by an individual's behavior reactions when their freedom is restricted [9]. From the perspective of reactance $[18,24]$, viewers who are forced into exposure to an in-stream ad can have psychological reactance that prompts them to click the skip-ad button, resulting in higher ad avoidance. The final and most important antecedent of ad avoidance is irritation [22]. When ads are offensive or overly manipulative, viewers are likely to perceive ads as unwanted irritation [23], and it is the main reason why viewers can be distracted from and dislike the ads.

\subsection{Ad Irritation and Its Effect on Ad Avoidance}

Ad irritation refers to the extent to which a viewer perceives ad content and strategies as offensive and annoying [25]. Many studies have indicated that ad content (e.g., messy, untrue, and exaggerated), execution (e.g., goal interruption), and placement (e.g., appearing too frequently) can trigger viewers to perceive ad irritation [24-28]. These studies have pointed out that as long as viewers have a way to avoid ads (e.g., clicking skip-ad button), they will do so [22,23]. In fact, ad irritation can cause viewers' unfavorable attitudes toward ads, reducing ad values and effectiveness [29]. The perspective of intrusiveness also suggests that viewers get tired of ads on in-stream media because they have to wait for the content of their choice to start [24]. For instance, when viewers aim to watch specific video content on YouTube and an unexpected in-stream ad interrupts their viewing, they are likely to have irritating experiences, increasing resistance to the ad $[9,24]$. Thus, following prior studies, we expect that perceived ad irritation can lead viewers to ad avoidance. We propose the following controlled hypothesis because much research has demonstrated it:

Controlled Hypothesis. Ad irritation is positively related to ad avoidance on YouTube channels.

For the audience, informing viewers of good reasons for watching in-stream ads can reduce their ad avoidance [9]. Thus, it is important to make ads valuable to viewers and thereby lead them to feel that watching ads is not "a waste of time" [11,30]. This solution requires that ad content carefully match viewers' interests or values based on their viewing behaviors $[25,31]$. However, matching all viewers' interests and preferences is very difficult. Studying what other potential mechanisms can reduce ad irritation and avoidance on YouTube remains a critical issue. To fulfill such a knowledge gap, this study draws upon 
the source-attractiveness theory [12,32] and the perspective of reciprocal altruism [14] as the theoretical foundation to develop a research model (see Figure 1). This research argues that source attractiveness and reciprocal altruism are key mitigators for ad irritation and avoidance on YouTube channels.

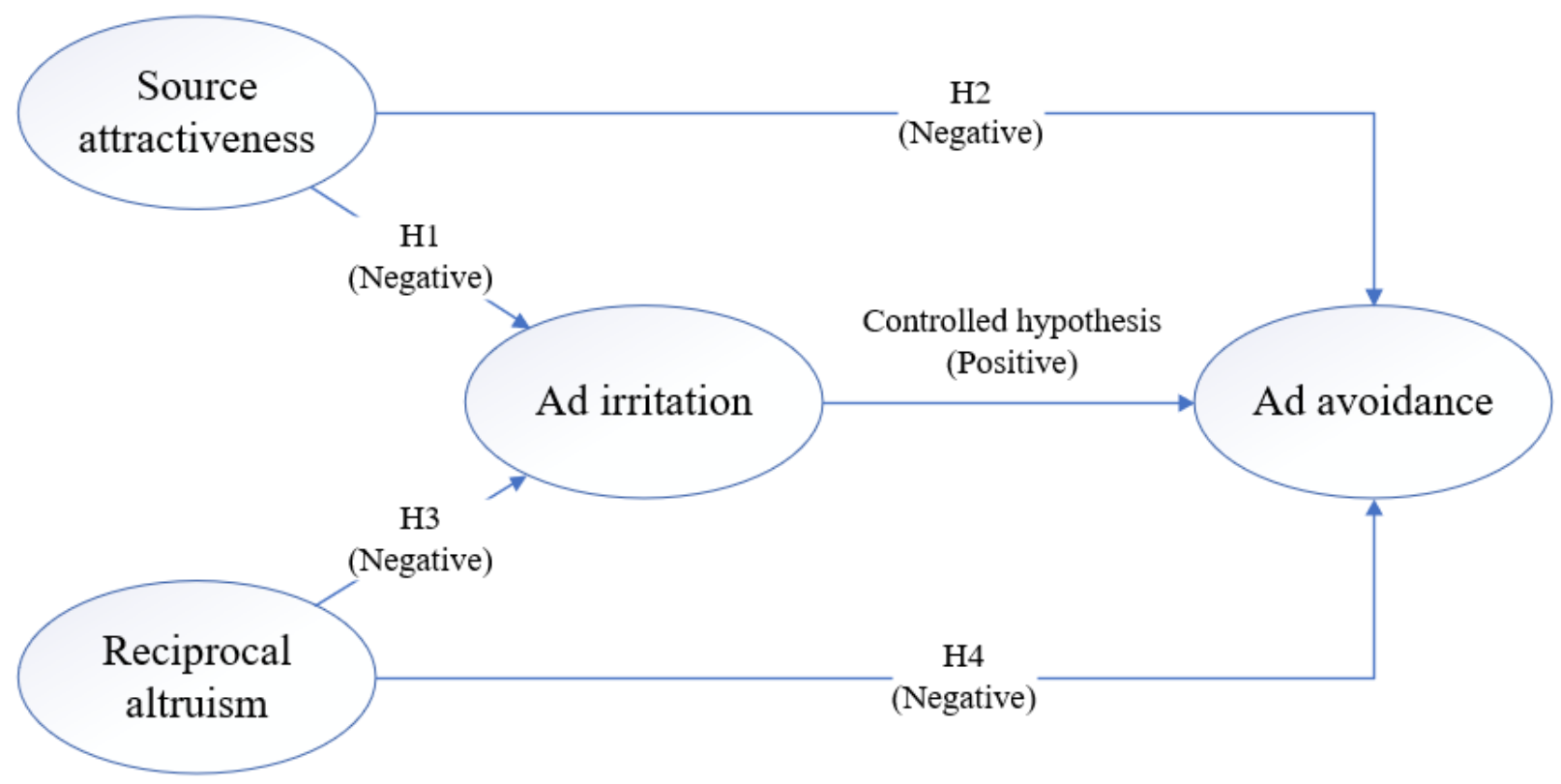

Figure 1. Research model.

\subsection{Source Attractiveness and Its Effects on Ad Irritation and Ad Avoidance}

The source-attractiveness theory rests on the social psychology research [32]. According to McGuire [33], source attractiveness is considered attractive and persuasive to people. Source attractiveness includes three interrelated aspects, namely similarity, familiarity, and likability [33]. Similarity is the supposed resemblance between a source and a receiver of a message. When people consider celebrity endorsers similar to them, they find this celebrity more attractive. Familiarity is defined as that a receiver feels familiar with the knowledge of a source through exposure. Likability reflects a receiver's positive emotional experiences and affection for a source of physical appearance, behaviors, or other personal traits (talent, personality, etc.) [34,35].

The source-attractiveness theory provides several insights for the research on celebrity endorsements. McGuire [33] demonstrates that celebrities' certain roles in promotion are devices to their credibility and attractiveness. Fleck et al. [36] show that celebrity likability positively affects their predisposition toward ads, which in turn facilitates receivers' brand beliefs and willingness to buy. For the same reason, celebrities develop a persona through the types of roles they play in society and form their image in the media (Amos et al., 2008). Chekima et al. [37] also demonstrate a positive relationship between celebrity source attractiveness and ad effectiveness. They prove that viewers buy products because they like their endorsers. Overall, the source-attractiveness theory explains that people have positive attitudes toward an ad, a brand, and purchase intentions when they really like a celebrity endorser [36-38]. Accordingly, we extend this theory to the context of YouTube channels.

As argued above, watching in-streaming ads and waiting for them to end so that the selected content can start are irritating to viewers $[9,39]$. However, how viewers interpret in-stream ads can be traced to their affection in nature [12]. That is, the source attractiveness of creators may affect viewers' attitudes toward in-stream ads. Since viewers watch creators' videos and get more information about the creators, the viewers become more familiar with and gain more trust in the creators, creating more concrete relationships with the creators. Such familiarity can further lead viewers to seek out their commonalities with the creators, 
increasing perceived similarity and likability $[38,40]$. Thus, viewers tend to find the creators more attractive, and the viewers' attitudes toward the content and ads emerging from the channels would be more positive. Such attitude extension from source attractiveness is likely to increase viewers' willingness to watch in-stream ads, reducing their irritated feelings. Accordingly, we expect that source attractiveness can reduce ad irritation:

Hypothesis 1 (H1). Source attractiveness is negatively related to ad irritation on YouTube channels.

Based on the source-attractiveness theory [32,33], Back et al. [41] find that the longer an individual is exposed to another person, the more the individual rates that person positively and wants to interact with him/her every day. Following this logic, the longer viewers subscribe and follow a creator, the more the viewers become familiar with the creator, creating closer relationships between the viewers and the creator. Viewers, in order to keep their sense of familiarity with a creator, may continue to subscribe to a channel to maintain their relationships with the creator. Thus, watching in-stream ads on the channel is not a "waste of time" thing for the viewers $[9,19]$. Moreover, when viewers perceive a creator as similar to them, they tend to find the creator more attractive, irresistibly leading them to keep in touch with the creator. Thus, viewers are likely to subscribe to channels of creators that are similar to them and willing to spend time watching ads on those channels in order to see more content from the channels. By doing so, the creators will obtain sufficient profits to continue filming. That is, viewers no longer consider watching in-stream ads meaningless but rather know that it can provide support for the creators. Finally, when viewers like a creator and subscribe to his or her channel, they can generate interpersonal trust in the creator [42] and express their affection by watching in-stream ads on the channel. Overall, we argue that source attractiveness can change viewers' perception of in-stream ads from negative to positive, reducing ad avoidance:

Hypothesis 2 (H2). Source attractiveness is negatively related to ad avoidance on YouTube channels.

\subsection{Reciprocal Altruism and Its Effects on Ad Irritation and Ad Avoidance}

Altruism, defined as the willingness to increase the welfare of others, is the opposite of selfishness [43]. Altruism can purely be the desire to help others for more self-interested reasons [44], and it can be extended to a similar concept, namely reciprocal altruism [14]. This is that one person makes a small sacrifice for another and expects to be rewarded [45]. White and Peloza [46] suggest that reciprocal altruism arises from two actors, each acting out of selfish self-interest to promote the well-being of the other. The social exchange theory (SET) can further explain the effectiveness of self-interest claims [47,48]. According to the SET, people invest in relations based on their cost-benefit comparison level, and people evaluate the expected value of the relations before proceeding with their actions $[48,49]$. The resources may be tangible (e.g., goods or money) or intangible (e.g., social amenities, friendships, or reputations) [50]. Thus, people may be reciprocally altruistic with each other by providing various tangible or intangible resources to each other.

Reciprocal altruism has been documented in the fields of psychology, economics, marketing, and tourism [44]. For instance, Shiau and Chau [51] discuss whether customer altruistic behaviors affect online group-buying behaviors. Chiang and Hsiao [52] demonstrate that sharers gain expected benefits (e.g., enhancements of their reputation and social statuses) and are willing to help others, and that therefore, reciprocal altruism increases their continued motivation for sharing videos. Similar to these studies, we extend this concept to the contexts of watching in-stream ads on YouTube channels. We argue that viewers of reciprocal altruism are more willing to watching in-stream ads.

As mentioned above, ad irritation can be mitigated when viewers understand the meaning of watching in-stream ads $[9,53]$. Viewers of reciprocal altruism are likely to regard watching in-stream ads as a voluntary and reciprocal behavior because of advertising profitsharing mechanisms on YouTube. Thus, reciprocally altruistic viewers consider watching in-stream ads as an indispensable driving force for evolving YouTube channels. This is a 
good reason for viewers to reduce their negative attitudes toward in-stream ads, mitigating ad irritation. Thus, we propose:

Hypothesis 3 (H3). Reciprocal altruism is negatively related to ad irritation on YouTube channels.

According to the SET, viewers are willing to establish reciprocal interpersonal relationships with creators they believe in [54]. Expected reciprocal benefits, such as continuing to publish good (or even similar) quality videos by creators, increase viewers' willingness to watch in-stream ads. Watching in-stream ads can become a way for viewers to use emotional reactions to achieve their goals and help creators keep their channels running. Thus, viewers develop an emotional attachment to their exchange partners (i.e., creators), enhancing their ads watching motivation. Accordingly, we propose:

Hypothesis 4 (H4). Reciprocal altruism is negatively related to ad avoidance on YouTube channels.

\section{Methodology}

In this section, we will introduce the methodology that we adopt to collect empirical data and examine our hypotheses and the research model. Our research findings will also be presented in the end of this section.

In this study, the main research question is to explore what and how we can increase viewers' motivation for watching in-stream ads and reduce their ad irritation and avoidance. We aim to examine the mitigating effects of source attractiveness and reciprocal altruism on ad irritation and avoidance. Specifically, we propose a variance model with four hypotheses (H1-4) based on the aspects of source attractiveness and reciprocal altruism. In order to examine our variance model, we adopted the quantitative method with survey and structural equation modeling. This method is more appropriate in this study because our purpose, conceptually, is to seek explanations of continuous change driven by deterministic causation, with independent variables causing changes in dependent variables [55]. That is, we seek to examine that source attractiveness and reciprocal altruism can cause negative changes in ad irritation and avoidance. This purpose is difficult to achieve by the qualitative method, because it is mainly adopted in the process model and used to explore entities participating in events, activities, and choices over time [55].

An online questionnaire was utilized to collect empirical data. This approach has several advantages over traditional paper-based surveys, such as rapid response time and cost efficiency [56]. More importantly, our research population is online viewers on YouTube who should be more familiar with online questionnaire. The questionnaires consisted of two parts. In the first part, the respondents were asked questions regarding their demographic variables, including their gender, age, education level, monthly income, daily time spent on YouTube, and the frequency of their video watching on a selected channel. In the second part, the respondents were asked about measurement items in terms of our research constructs (see Appendix A). The respondents were asked to recall their favorite or a familiar creator's channel as an answering target. All items were measured on a seven-point Likert scale, ranging from 1 (strongly disagree) to 7 (strongly agree).

Ad avoidance was measured by seven items adapted from Cho and Choeon [6]. It assesses the extent to which a viewer reduces their exposure to YouTube skippable instream ads by cognitive, affective, and behavioral means. Ad irritation was measured by eight items adapted from Baek and Morimoto [8] and Fritz [57]. It assesses the extent to which a viewer perceives negative experiences of watching in-stream ads on a YouTube channel. Source attractiveness was measured by six items adapted from Choi and Rifon [58], Kiecker and Cowles [34], Teng et al. [59], and Wangenheim and Bayón [60]. It assesses the degree of similarity, familiarity, and likability of a viewer on a creator. Reciprocal altruism was measured by seven items adapted from Chiang and Hsiao [52], Hsu and Lin [43], and Shiau and Chau [51]. It assesses how well a viewer is willing to benefit a creator in return. 


\subsection{Sample Characteristics}

We controlled perceived ad personalization, perceived ad intrusiveness, the ages of our participants, the frequency of video watching on a selected channel, and the monthly income of our participants. The literature has indicated that ad personalization is crucial in optimizing advertising messages that match viewers' interests and preferences [8]. Research has also proved that the ad personalization is closely related to the relevance of ads and causes viewers to reduce the reflection of ad avoidance. Ad intrusiveness is a concept used to explain why viewers regard advertising as irritating. When ads effectively restrict the actions of viewers, they feel irritated and thus may increase ad irritation. Finally, we controlled demographic variables such as age and income because past research had pointed out that viewers with different demographics responded differently to advertising [39].

Considering the validity of the sample, only those respondents who indicated familiarity with YouTube and used it for at least one hour per day were asked to complete the questionnaire. We placed survey messages and links to a URL on the biggest YouTube forum-Dcard in Taiwan-and left messages on the Top 100 YouTube channels surveyed by the Dailyview Network (https:/ / dailyview.tw / accessed on 15 July 2020) in Taiwan. These two survey approaches were chosen because of their wide reach and popularity in Taiwan. In total, 512 valid responses were received. Table 1 summarizes the characteristics of the respondents.

Table 1. Characteristics of respondents $(N=512)$.

\begin{tabular}{|c|c|c|}
\hline Characteristics & Frequency & $\%$ of Total \\
\hline \multicolumn{3}{|l|}{ Gender } \\
\hline Male & 170 & 33.2 \\
\hline Female & 342 & 66.8 \\
\hline \multicolumn{3}{|l|}{ Age } \\
\hline$<19$ & 146 & 28.6 \\
\hline $20-30$ & 320 & 62.7 \\
\hline $31-40$ & 34 & 6.64 \\
\hline $41-50$ & 5 & 0.97 \\
\hline$>50$ & 5 & 0.97 \\
\hline \multicolumn{3}{|l|}{ Education } \\
\hline High School & 117 & 22.9 \\
\hline Five-year program & 13 & 2.5 \\
\hline College & 294 & 57.4 \\
\hline Master & 81 & 15.8 \\
\hline $\mathrm{PhD}$ & 2 & 0.4 \\
\hline Other & 5 & 1.0 \\
\hline \multicolumn{3}{|l|}{ Monthly income } \\
\hline$<22 \mathrm{~K}$ & 336 & 65.8 \\
\hline $20-29 \mathrm{~K}$ & 58 & 11.2 \\
\hline $30-39 \mathrm{~K}$ & 66 & 12.9 \\
\hline $40-49 \mathrm{~K}$ & 31 & 6.1 \\
\hline$>50 \mathrm{~K}$ & 21 & 4.1 \\
\hline
\end{tabular}


Table 1. Cont.

\begin{tabular}{lcc}
\hline \multicolumn{1}{c}{ Characteristics } & Frequency & \% of Total \\
\hline Daily time spent on YouTube & 61 & \\
\hline$<1 \mathrm{~h}$ & 227 & 54.1 \\
\hline $1-2 \mathrm{~h}$ & 42 & 8.2 \\
\hline $2-3 \mathrm{~h}$ & 65 & 12.7 \\
\hline $3-4 \mathrm{~h}$ & 29 & 5.7 \\
\hline $4-5 \mathrm{~h}$ & 38 & 7.4 \\
\hline$>5 \mathrm{~h}$ & & \\
\hline The frequency of video watching on the selected channel & & \\
\hline ten-point scale, ranging from 1 (very few) to 10 (very much)) & 4 & 0.8 \\
\hline 1 & 6 & 1.2 \\
\hline 2 & 6 & 1.2 \\
\hline 3 & 7 & 1.4 \\
\hline 4 & 15 & 2.9 \\
\hline 5 & 28 & 5.5 \\
\hline 6 & 51 & 10.0 \\
\hline 7 & 75 & 14.6 \\
\hline 8 & 77 & 15.0 \\
\hline 9 & 243 & 47.5 \\
\hline 10 & &
\end{tabular}

\subsection{Measurement Model}

Partial least squares (PLS) using SmartPLS 3.3.3 was conducted for measurement validation and hypothesis testing. We assessed the validity and reliability based on Hair [61]. Outer loadings for all items were higher than 0.70 and significant at the $1 \%$ level except for nine items (AA1, AA3, PI1, PI2, SA1, SA4, SA5 RA1, and RA3). Following Hair [61], we analyzed the impacts of item deletions on the internal consistency reliability of each construct, resulting in four items being deleted (PI1, AA1, AA3, RA1). Then, we tested the model fit with standardized root mean square residuals (SRMRs). The SRMRs of the saturated model and the estimated model were 0.06 , which were lower than the cut-off value of 0.08 , indicating a good model fit [61]. The rho_A, composite reliability (CR), and Cronbach's alpha estimates (see Table 2) were above 0.8 , indicating a good internal consistency and the reliability of all the scales. We further evaluated the convergent validity using an average variance extracted (AVE) criterion [61]. The AVEs of all constructs exceeded the minimum threshold value of 0.5 , demonstrating the sufficient convergent validity.

Table 2. Reliability and validity measures.

\begin{tabular}{cccccc}
\hline Construct & Item & rho_A & Cron. $\alpha$ & CR. & AVE \\
\hline Ad avoidance & 5 & 0.82 & 0.83 & 0.88 & 0.59 \\
\hline Ad irritation & 9 & 0.93 & 0.93 & 0.94 & 0.63 \\
\hline Reciprocal altruism & 6 & 0.83 & 0.83 & 0.88 & 0.54 \\
\hline Source attractiveness & 6 & 0.86 & 0.97 & 0.88 & 0.56 \\
\hline Perceived ad intrusiveness & 6 & 0.88 & 0.89 & 0.91 & 0.62 \\
\hline Perceived ad personalization & 4 & 0.83 & 0.83 & 0.89 & 0.66 \\
\hline
\end{tabular}


Discriminant validity is established when (1) items compared with other constructs have a higher load on the construct to be measured, (2) the square root of the AVE by each construct is larger than the inter-construct correlations, and (3) the heterotrait-monotrait ratio of correlation (HTMT) is significantly smaller than 1 [61]. Our data showed that all the items loaded were higher on their own construct than those on other constructs (see Appendix B). As shown in Table 3, the square roots of AVE of all constructs were greater than the absolute values of the correlation coefficient between the constructs. The HTMT values presented in the parentheses of Table 3 were significantly lower than 1, with a 95\% confidence interval. These results indicated the discriminant validity.

Table 3. Fornell-Larcker criterion and HTMT.

\begin{tabular}{|c|c|c|c|c|c|c|}
\hline Construct & AA & AI & PI & $\mathbf{R A}$ & SA & PA \\
\hline Ad avoidance & 0.76 & & & & & \\
\hline Ad irritation & $\begin{array}{c}0.56 \\
(0.06)\end{array}$ & 0.79 & & & & \\
\hline Perceived ad intrusiveness & $\begin{array}{c}0.40 \\
(0.46)\end{array}$ & $\begin{array}{c}0.59 \\
(0.64)\end{array}$ & 0.79 & & & \\
\hline Reciprocal altruism & $\begin{array}{c}-0.34 \\
(0.41)\end{array}$ & $\begin{array}{c}-0.34 \\
(0.38)\end{array}$ & $\begin{array}{l}-0.21 \\
(0.24)\end{array}$ & 0.73 & & \\
\hline Source attractiveness & $\begin{array}{c}-0.13 \\
(0.13)\end{array}$ & $\begin{array}{c}-0.04 \\
(0.06)\end{array}$ & $\begin{array}{c}-0.04 \\
(0.07)\end{array}$ & $\begin{array}{c}0.51 \\
(0.58)\end{array}$ & 0.75 & \\
\hline Perceived ad personalization & $\begin{array}{l}-0.15 \\
(0.17)\end{array}$ & $\begin{array}{l}-0.12 \\
(0.14)\end{array}$ & $\begin{array}{l}-0.04 \\
(0.17)\end{array}$ & $\begin{array}{c}0.15 \\
(0.19)\end{array}$ & $\begin{array}{l}-0.02 \\
(0.10)\end{array}$ & 0.81 \\
\hline
\end{tabular}

Note: (1) Square roots of average variance extracted are shown on the diagonal; (2) HTMT is shown in parentheses.

Common method variance (CMV) was tackled by two approaches. First, we used Harman's single-factor test to detect CMV [62]. Eight factors with an eigenvalue $>1$ were extracted and collectively accounted for $65.5 \%$ of the variances in the data, with the first factor accounting for $24.52 \%$ of the variances. No factors accounted for more than $50 \%$. Second, we incorporated the measured latent marker variable (MLMV) in our survey to correct CMV when using PLS [63]. This approach requires collecting multiple items that have no nomological relationship with the research items. We followed the guidelines introduced by Chin et al. [63]. We adopted the items, which were used to measure "trying new features" in Microsoft Office [64], as a marker variable. Then, we could conduct the construct level correction (CLC) to partial out the CMV effects at the structural model in our data analysis [63]. CLC involves creating as many CMV control constructs as there are constructs in a research model. Each CMV control uses the same entire set of MLMV items. A CMV construct is modeled so as to impact on each model construct [63]. The results indicated no change of the correlation signs of path coefficients and significances in our structural model. Thus, we concluded that CMV was not a serious problem.

\subsection{Structural Model and Findings}

We first assessed the multicollinearity by examining exogenous constructs separately for each subpart of the research model [61]. All VIF of endogenous constructs were less than 4, which was well below the threshold value of 5 [61], indicating no multicollinearity problem in our model. To assess the significance of the structural model, SmartPLS was applied to a bootstrapping procedure with a resample of 10,000 . The full model has an $\mathrm{R}^{2}$ of $37 \%$ for ad avoidance and $42 \%$ for ad irritation. With an omission distance equaling 7 , all cross-validated redundant $\mathrm{Q}^{2}$ values of endogenous structures are greater than zero, indicating a predictive correlation.

As shown in Figure 2, the results demonstrate that ad irritation raised by skippable in-stream ads on YouTube channels positively affects ad avoidance $(\beta=0.422 ; p<0.01)$. The results confirm our controlled hypothesis and are consistent with results of prior 
studies $[8,9,22]$. The direct path from source attractiveness to ad irritation is positive with a coefficient of 0.146 at the $p<0.05$ level. However, this is opposite to our argument, thus rejecting H1. We will discuss this result below. Our results also show that source attractiveness does not reduce ad avoidance, rejecting H2 ( $\beta=0.016 ; p>0.05)$. However, we find that reciprocal altruism is negatively associated with ad irritation (supporting H3; $\beta=-0.208 ; p<0.01$ ) and ad avoidance (supporting H4; $\beta=-0.154 ; p<0.05$ ). Such results lead us to further conduct an additional test to understand whether reciprocal altruism moderates the relationship between ad irritation and avoidance. The result shows that the moderating effect is insignificant $(\beta=0.008 ; p>0.5)$. Nevertheless, we still demonstrate that reciprocal altruism can reduce viewers' ad irritation and avoidance. Overall, we note support for two of the four hypotheses in the research model.

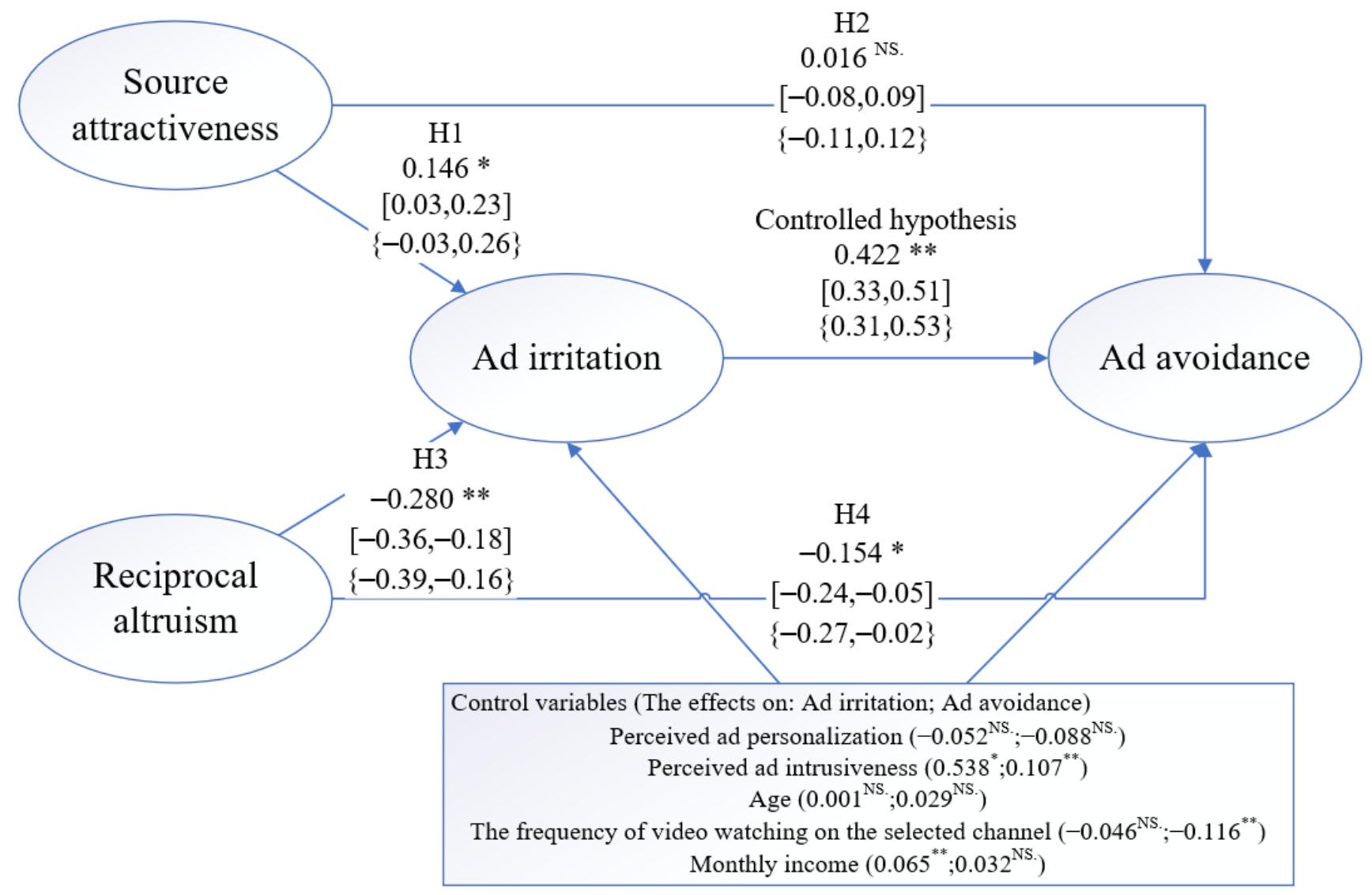

Figure 2. Structural model. Note: ${ }^{* *} p<0.01 ;{ }^{*} p<0.05$; NS. Non-significant; CI bias corrected [2.5\%, 97.5\%]; $\{0.05 \%, 99.5 \%\}$.

\section{Results and Discussion}

In this section, we will present and discuss our research results. We will also show the interconnections between our research results and prior studies.

Consistent with prior studies that demonstrate the positive relationship between ad irritation and avoidance $[8,9,24]$, we find support for the controlled hypothesis that irritated feelings on YouTube skippable in-stream ads are highly related to avoiding the ads. That is, the more irritating an in-stream ad, the more likely a viewer clicks the "skip-ad" button. Since in-stream ads restrict and obstruct viewers' intended behaviors, viewers tend to become annoyed and, as a result, avoid the ads by clicking the skip-ad button, reducing ad values and effectiveness.

Surprisingly, source attractiveness cannot reduce ad irritation (H1) and avoidance (H2). However, source attractiveness can increase ad irritation. One possible reason can be attributed to viewers' YouTube viewing behaviors. Based on a consumer survey [65], $57 \%$ of viewers watched online videos for entertainment. Viewers choose specific or 
favorite creators' content to meet their needs so as to achieve gratification. However, in-stream ads that appear before, during, or after the content restrict viewers' viewing behaviors and interrupt them to see their favorite creators. Thus, from a perspective of resistance, in-stream ads can cause a slight reactance [8,22], highlighting ad irritation (H1). We consequently conclude that goal-oriented viewers are more likely to be irritated and hence skip in-stream ads.

This study demonstrates that reciprocal altruism can mitigate ad irritation (H3) and avoidance (H4). This provides a new perspective for understanding the psychological processes of reducing ad irritation and avoidance, whereas prior studies largely focus on the drivers of ad avoidance $[6,8,22]$. Specifically, our results reveal that when viewers behaviors are reciprocally altruistic toward creators and their channels, ad irritation and avoidance toward in-stream ads tend to be lower. As we argued above, viewers might find a good reason to watch in-stream ads, making them feel positive rather than irritative about watching ads. From the theoretical standpoint of reciprocal altruism, viewers can simultaneously obtain interests (e.g., creators consistently creating video content) while helping creators. Overall, our findings have shed new light on how ad irritation and avoidance can be reduced by reciprocal altruism.

\section{Conclusions, Implications, and Future Research}

In this section, we will conclude our research findings and results. Then, we provide insightful implications for both research and practice. We finally will indicate our research limitations and possible future research directions.

This study has demonstrated that in-stream ads on YouTube channels can irritate viewers to the extent that they tend to avoid the ads. When a channel's creator has source attractiveness for the viewers, the viewers are more likely to be irritated by in-stream ads. However, viewers of higher reciprocal altruism are likely to view in-stream ads as worth watching for the benefits of their favorite creators, thereby reducing ad avoidance. We believe that our research findings provide practical and theoretical insights for both creators and advertisers.

This study provides several theoretical implications for the research fields of ad avoidance. First, this study confirms that ad irritation plays an important role in enabling ad avoidance to in-stream ads in the context of YouTube channels [39]. Second, we reveal that reciprocal altruism can influence viewers' attitudes and reflecting behaviors toward in-stream ads. When viewers have emotional attachments with creators, reciprocal altruism can help viewers create powerful ties with the creators [44]. This means that while the negative feelings of viewers (i.e., ad irritation) can be reduced, their willingness to watch skippable in-stream ads can be increased. Finally, this study is the first research to show how reciprocal altruism can be used to lure viewers to watch skippable in-stream ads, and as a result, they may have positive attitudes and behaviors toward watching ads. Future studies can consider our model as a framework for reducing ad irritation and avoidance.

We also provide several managerial suggestions for the advertising practice on YouTube channels. In terms of creators, ads revenue is critical for YouTube creators to maintain their channels. We suggest that creators rethink why viewers are willing to watch ads and consider evoking their reciprocal altruistic behaviors. One way to encourage their viewers' altruistic behaviors is to make viewers feel that watching ads is not a waste of time. This can be done by directly reminding their viewers to increase their ad-watching behaviors. Creators can also enhance interpersonal attachments with their viewers by adding a "call to action" on videos, raising viewers' reciprocal altruism. When viewers understand that in-stream ads are important to creators on YouTube, the viewers may, as a result, reduce their ad irritation and avoidance. Another way to engage viewers to watch an in-stream ad is to include social exchange values in in-stream ads [59], such as altruism and philanthropy. A recent study has shown that a strong emotional ad delays viewers in skipping ads [66]. We also suggest to advertisers on YouTube channels that the initial few seconds of ads play a critical role to persuade viewers to watch the ads. Adding some 
reciprocal altruistic messages into the ads is more likely to motivate viewers to watch the ads. Overall, considering the trends of creating self-owned media, the findings of this paper are important for both beginner creators and advertisers. Therefore, creators and advertisers are advised to focus on reciprocal altruism and the behavioral consequences of interpersonal influences on in-stream ads.

However, this paper has several limitations. First, our samples mainly comprise users of a YouTube platform in Taiwan. Thus, the generalizability of our model and findings on other streaming platforms may require further investigations. Second, our study relies on self-reports as a single data source. This may have created a common method bias. Thus, we test for the common method bias, and there is no statistical evidence of a severe bias. Finally, our data are cross-sectional. Therefore, all the relationships in our study can only be tentatively concluded.

Finally, we suggest three future research directions. First, while this study mainly adopts quantitative methods to examine the research model, future research may adopt qualitative methods to deeply understand the mechanism of the mitigating effect of reciprocal altruism on ad irritation and ad avoidance. That is, qualitative methods can help researchers further explore why, when, and how can trigger viewers' reciprocal altruism and lure them to watch skippable in-stream ads. Second, although this study finds that source attractiveness can cause viewers to perceive ad irritation, future research can seek more insights about what characteristics of creators can increase viewers' ad irritation and what characteristics may bring opposite results. Finally, our empirical data were collected in Taiwan. Future study may conduct a multi-national or global range survey. This may provide insights about the comparisons of the mitigating effects of reciprocal altruism on ad irritation and ad avoidance across different countries.

Author Contributions: Conceptualization, H.C.-S.L., N.C.-A.L. and Y.-C.L.; Formal analysis, H.C.S.L., N.C.-A.L. and Y.-C.L.; Supervision, H.C.-S.L.; Writing-original draft, H.C.-S.L., N.C.-A.L. and Y.-C.L. All authors have read and agreed to the published version of the manuscript.

Funding: This research was supported in part by the Ministry of Science and Technology in Taiwan under contract number MOST 110-2511-H-130-002-.

Institutional Review Board Statement: Not applicable.

Informed Consent Statement: Not applicable.

Data Availability Statement: The data presented in this study are available on request from the corresponding author.

Conflicts of Interest: The authors declare no conflict of interest.

Appendix A

Table A1. Measurement Items.

\begin{tabular}{|c|c|c|c|}
\hline & Scale Indicators & Mean & S.D. \\
\hline \multicolumn{4}{|c|}{ Ad Avoidance } \\
\hline (AA1) & I intentionally ignore any YouTube skippable in-stream ads that appear on the creator channel. (deletion) & 4.75 & 1.87 \\
\hline (AA2) & $\begin{array}{l}\text { I intentionally don't put my eyes on YouTube skippable in-stream ads that appear on the } \\
\text { creator channel. }\end{array}$ & 4.51 & 1.70 \\
\hline (AA3) & $\begin{array}{l}\text { I intentionally don't pay attention to YouTube skippable in-stream ads that appear on the creator } \\
\text { channel. (deletion) }\end{array}$ & 3.88 & 1.75 \\
\hline (AA4) & I hate any YouTube skippable in-stream ads that appear on the creator channel. & 4.27 & 1.74 \\
\hline (AA5) & $\begin{array}{l}\text { It would be better if there were no YouTube skippable in-stream ads that appear on the } \\
\text { creator channel. }\end{array}$ & 4.87 & 1.86 \\
\hline (AA6) & I skip or click away any ads that appear on the creator channel. & 4.28 & 1.74 \\
\hline (AA7) & Overall, I do any action to avoid ads that appear on the creator channel. & 4.52 & 1.71 \\
\hline
\end{tabular}


Table A1. Cont.

\begin{tabular}{|c|c|c|c|}
\hline \multicolumn{2}{|r|}{ Scale Indicators } & Mean & S.D. \\
\hline \multicolumn{4}{|c|}{ Ad irritation } \\
\hline \multicolumn{4}{|c|}{ When I receive personalized advertising on [MEDIA TYPE ], I think it is ... . } \\
\hline (AI1) & Negative & 4.31 & 1.43 \\
\hline$(\mathrm{AI} 2)$ & Irritating & 4.67 & 1.51 \\
\hline$(\mathrm{AI} 3)$ & Pointless & 4.41 & 1.50 \\
\hline (AI4) & Unappealing & 4.61 & 1.47 \\
\hline (AI5) & Regressive & 4.40 & 1.43 \\
\hline (AI6) & Unattractive & 4.46 & 1.43 \\
\hline (AI7) & Vulgar & 4.28 & 1.53 \\
\hline (AI8) & Awful & 3.87 & 1.60 \\
\hline$(\mathrm{AI} 9)$ & $\begin{array}{l}\text { Overall, the extent to which I perceive the experience with YouTube skippable in-stream ads that } \\
\text { appear on the creator channel as troublesome. }\end{array}$ & 4.68 & 1.53 \\
\hline \multicolumn{4}{|c|}{ Source attractiveness } \\
\hline (SA1) & I am very familiar with this YouTube creator. & 5.54 & 1.01 \\
\hline (SA2) & I find this YouTube channel is attractive when I am familiar with this creator. & 5.47 & 1.05 \\
\hline (SA3) & This YouTube creator is similar to me in preferences and values. & 5.35 & 1.13 \\
\hline (SA4) & I find this YouTube channel is attractive when I have similar opinions with this creator. & 5.24 & 1.15 \\
\hline (SA5) & I like this YouTube creator very much. & 6.07 & 0.88 \\
\hline (SA6) & I find this YouTube channel attractive when I like this creator. & 6.00 & 0.93 \\
\hline \multicolumn{4}{|c|}{ Reciprocal altruism } \\
\hline (RA1) & I like helping this creator on YouTube. (deletion) & 5.22 & 1.11 \\
\hline (RA2) & It feels good to help this creator by spending time and money through YouTube. & 5.30 & 1.15 \\
\hline (RA3) & Spending time and money to help this creator bring me happiness. & 5.71 & 1.05 \\
\hline (RA4) & I tend to do something to support the YouTube creator/creator group. & 4.77 & 1.13 \\
\hline (RA5) & $\begin{array}{l}\text { I tend to do something to help the YouTube creator/creator group, as they provide free videos for } \\
\text { everyone to watch. }\end{array}$ & 4.98 & 1.16 \\
\hline (RA6) & $\begin{array}{l}\text { I intend to take action to help the YouTube creator/creator group, instead of watching } \\
\text { videos selfishly. }\end{array}$ & 4.12 & 1.27 \\
\hline (RA7) & $\begin{array}{l}\text { I intend to take action to support the YouTube creator/creator group for them to keep running } \\
\text { the channel. }\end{array}$ & 4.48 & 1.20 \\
\hline \multicolumn{4}{|c|}{ Perceived ad intrusiveness } \\
\hline \multicolumn{4}{|c|}{ When I receive YouTube skippable-ads, I thought it was ... . } \\
\hline (PI1) & distracting (deletion) & 5.07 & 1.30 \\
\hline (PI2) & disturbing & 3.36 & 1.41 \\
\hline (PI3) & forced & 4.47 & 1.72 \\
\hline (PI4) & interfering & 5.02 & 1.56 \\
\hline (PI5) & intrusive & 4.17 & 1.69 \\
\hline (PI6) & invasive & 3.17 & 1.50 \\
\hline (PI7) & obtrusive & 4.79 & 1.59 \\
\hline \multicolumn{4}{|c|}{ Perceived ad personalization } \\
\hline (PP1) & The skippable in-stream ads on YouTube make purchase recommendations that match my needs. & 3.66 & 1.52 \\
\hline (PP2) & Skippable in-stream ads on YouTube make me feel that I am a unique customer. & 2.89 & 1.36 \\
\hline (PP3) & I believe that skippable in-stream ads on YouTube are customized to my needs. & 3.43 & 1.61 \\
\hline (PP4) & Overall, skippable in-stream ads on YouTube are tailored to my situation. & 3.52 & 1.60 \\
\hline
\end{tabular}




\section{Appendix B}

Table A2. Cross-Loadings.

\begin{tabular}{|c|c|c|c|c|c|c|}
\hline Constructs & 1 & 2 & 3 & 4 & 5 & 6 \\
\hline \multicolumn{7}{|l|}{ Ad Avoidance } \\
\hline AA2 & 0.67 & 0.34 & 0.22 & -0.08 & -0.20 & -0.09 \\
\hline $\mathrm{AA} 4$ & 0.81 & 0.52 & 0.35 & -0.18 & -0.25 & -0.07 \\
\hline AA5 & 0.80 & 0.44 & 0.30 & -0.15 & -0.36 & -0.14 \\
\hline AA6 & 0.79 & 0.42 & 0.33 & -0.05 & -0.23 & -0.12 \\
\hline AA7 & 0.74 & 0.38 & 0.30 & -0.08 & -0.20 & -0.08 \\
\hline \multicolumn{7}{|l|}{ Ad Irritation } \\
\hline AI1 & 0.42 & 0.74 & 0.49 & -0.03 & -0.23 & 0.02 \\
\hline $\mathrm{AI} 2$ & 0.50 & 0.81 & 0.55 & -0.09 & -0.20 & -0.02 \\
\hline AI3 & 0.43 & 0.79 & 0.45 & -0.09 & -0.27 & -0.01 \\
\hline $\mathrm{AI} 4$ & 0.43 & 0.83 & 0.44 & -0.15 & -0.23 & -0.05 \\
\hline AI5 & 0.31 & 0.77 & 0.40 & -0.04 & -0.29 & -0.03 \\
\hline AI6 & 0.41 & 0.84 & 0.45 & -0.08 & -0.23 & -0.05 \\
\hline AI7 & 0.30 & 0.80 & 0.443 & -0.06 & -0.30 & -0.03 \\
\hline AI8 & 0.35 & 0.82 & 0.45 & -0.09 & -0.26 & -0.03 \\
\hline AI9 & 0.66 & 0.72 & 0.47 & -0.19 & -0.33 & -0.06 \\
\hline \multicolumn{7}{|l|}{ Perceived Intrusiveness } \\
\hline PI2 & 0.19 & 0.43 & 0.69 & 0.17 & -0.11 & -0.05 \\
\hline PI3 & 0.35 & 0.49 & 0.83 & -0.08 & -0.20 & -0.06 \\
\hline PI4 & 0.37 & 0.47 & 0.83 & -0.12 & -0.20 & 0.01 \\
\hline PI5 & 0.38 & 0.53 & 0.87 & -0.05 & -0.17 & -0.01 \\
\hline PI6 & 0.25 & 0.40 & 0.72 & 0.12 & -0.10 & -0.09 \\
\hline PI7 & 0.31 & 0.45 & 0.78 & -0.16 & -0.18 & 0.00 \\
\hline \multicolumn{7}{|l|}{ Perceived Personalization } \\
\hline PP1 & -0.12 & -0.09 & -0.08 & 0.74 & 0.10 & -0.01 \\
\hline PP2 & -0.14 & -0.06 & -0.00 & 0.77 & 0.12 & -0.09 \\
\hline PP3 & -0.10 & -0.12 & -0.04 & 0.89 & 0.12 & -0.02 \\
\hline PP4 & -0.12 & -0.13 & -0.01 & 0.84 & 0.15 & 0.03 \\
\hline \multicolumn{7}{|l|}{ Reciprocal Altruism } \\
\hline RA2 & -0.29 & -0.27 & -0.12 & 0.07 & 0.75 & 0.05 \\
\hline RA3 & -0.23 & -0.24 & -0.16 & 0.08 & 0.67 & 0.46 \\
\hline RA4 & -0.24 & -0.23 & -0.16 & 0.06 & 0.78 & 0.42 \\
\hline RA5 & -0.24 & -0.25 & -0.16 & 0.13 & 0.73 & 0.29 \\
\hline RA6 & -0.26 & -0.25 & -0.16 & 0.21 & 0.74 & 0.27 \\
\hline RA7 & -0.25 & -0.26 & -0.17 & 0.13 & 0.73 & 0.31 \\
\hline \multicolumn{7}{|l|}{ Source Attractiveness } \\
\hline SS1 & -0.05 & 0.02 & -0.04 & 0.03 & -0.04 & 0.67 \\
\hline SS2 & -0.06 & 0.00 & -0.02 & 0.01 & -0.02 & 0.69 \\
\hline SS3 & -0.14 & -0.05 & -0.05 & -0.06 & -0.05 & 0.89 \\
\hline SS4 & -0.13 & -0.04 & -0.06 & -0.10 & -0.06 & 0.89 \\
\hline SS5 & -0.06 & -0.04 & 0.03 & 0.11 & 0.03 & 0.71 \\
\hline SS6 & -0.05 & -0.01 & 0.02 & 0.06 & 0.02 & 0.06 \\
\hline
\end{tabular}

\section{References}

1. Wikipedia. YouTube. Available online: https://en.wikipedia.org/wiki/YouTube (accessed on 3 September 2021).

2. Mohsin, M. 10 Youtube Stats Every Marketer Should Know in 2021. Available online: https://www.oberlo.com/blog/youtubestatistics (accessed on 1 September 2021).

3. Statista. Most Popular Social Networks Worldwide as of July 2021, Ranked by Number of Active Users. Available online: https: //www.statista.com/statistics/272014/global-social-networks-ranked-by-number-of-users/ (accessed on 1 September 2021).

4. Omnicore. YouTube by the Numbers: Stats, Demographics \& Fun Facts. Available online: https://www.omnicoreagency.com/ youtube-statistics / (accessed on 1 September 2021).

5. YouTube. Non-Skippable Video Ads. Available online: https://support.google.com/youtube/answer/188038?hl=en (accessed on 1 September 2021). 
6. Cho, C.-H.; Choeon, H.J. Why do people avoid advertising on the internet? J. Advert. 2004, 33, 89-97. [CrossRef]

7. Dodoo, N.A.; Wen, J. Weakening the avoidance bug: The impact of personality traits in ad avoidance on social networking sites. J. Mark. Commun. 2021, 27, 457-480. [CrossRef]

8. Baek, T.H.; Morimoto, M. Stay away from me. J. Advert. 2012, 41, 59-76. [CrossRef]

9. Jeon, Y.A.; Son, H.; Chung, A.D.; Drumwright, M.E. Temporal certainty and skippable in-stream commercials: Effects of ad length, timer, and skip-ad button on irritation and skipping behavior. J. Interact. Mark. 2019, 47, 144-158. [CrossRef]

10. Kelly, L.; Kerr, G.; Drennan, J. Avoidance of Advertising in Social Networking Sites. J. Interact. Advert. 2010, 10, 16-27. [CrossRef]

11. Chen, J.-L.; Panyaruang, C. Attitudes of Young Consumers in Chiang Mai, Thailand toward YouTube Online Video and Audio Advertising. Adv. Manag. Appl. Econ. 2021, 11, 73-86. [CrossRef]

12. Yilmaz, C.; Eser Telci, E.; Bodur, M.; Eker Iscioglu, T. Source characteristics and advertising effectiveness: The roles of message processing motivation and product category knowledge. Int. J. Advert. 2011, 30, 889-914. [CrossRef]

13. Brajnik, G.; Gabrielli, S. A review of online advertising effects on the user experience. Int. J. Hum. Comput. Interact. 2010, 26, 971-997. [CrossRef]

14. Carter, G.; Chen, M.-H.; Razik, I. The Theory of Reciprocal Altruism. In The SAGE Handbook of Evolutionary Psychology: Foundations of Evolutionary Psychology; Shackelford, T.K., Ed.; SAGE: London, UK, 2020; p. 170.

15. Lee, J.; Kim, S.; Ham, C.-D. A double-edged sword? Predicting consumers' attitudes toward and sharing intention of native advertising on social media. Am. Behav. Sci. 2016, 60, 1425-1441. [CrossRef]

16. Speck, P.S.; Elliott, M.T. Predictors of advertising avoidance in print and broadcast media. J. Advert. 1997, 26, 61-76. [CrossRef]

17. van der Goot, M.J.; Rozendaal, E.; Opree, S.J.; Ketelaar, P.E.; Smit, E.G. Media generations and their advertising attitudes and avoidance: A six-country comparison. Int. J. Advert. 2018, 37, 289-308. [CrossRef]

18. Youn, S.; Kim, S. Understanding ad avoidance on Facebook: Antecedents and outcomes of psychological reactance. Comput. Hum. Behav. 2019, 98, 232-244. [CrossRef]

19. Semerádová, T.; Weinlich, P. The (In)Effectiveness of In-Stream Video Ads: Comparison of Facebook and YouTube. In Research Anthology on Strategies for Using Social Media as a Service and Tool in Business; IGI Global: Hershey, PA, USA, 2021 ; pp. $668-687$.

20. Pashkevich, M.; Dorai-Raj, S.; Kellar, M.; Zigmond, D. Empowering online advertisements by empowering viewers with the right to choose: The relative effectiveness of skippable video advertisements on YouTube. J. Advert. Res. 2012, 52, 451-457. [CrossRef]

21. Hall, M. How Do People Make Money on YouTube? Available online: https://www.investopedia.com/ask/answers/012015 /how-do-people-make-money-videos-they-upload-youtube.asp (accessed on 3 September 2021).

22. Seyedghorban, Z.; Tahernejad, H.; Matanda, M.J. Reinquiry into advertising avoidance on the internet: A conceptual replication and extension. J. Advert. 2016, 45, 120-129. [CrossRef]

23. Li, X.; Zhang, Y.; Yao, J. Avoidance Behavior toward Social Network Advertising: Dimensions and Measurement. In Proceedings of the WHICEB 2020, Wuhan, China, 5 July 2020.

24. Edwards, S.M.; Li, H.; Lee, J.-H. Forced exposure and psychological reactance: Antecedents and consequences of the perceived intrusiveness of pop-up ads. J. Advert. 2002, 31, 83-95. [CrossRef]

25. Raditya, D.; Gunadi, W.; Setiono, D.; Rawung, J. The Effect of Ad Content and Ad Length on Consumer Response towards Online Video Advertisement. Winners 2020, 21, 119-128. [CrossRef]

26. Aaker, D.A.; Bruzzone, D.E. Causes of irritation in advertising. J. Mark. 1985, 49, 47-57. [CrossRef]

27. Dehghani, M.; Niaki, M.K.; Ramezani, I.; Sali, R. Evaluating the influence of YouTube advertising for attraction of young customers. Comput. Hum. Behav. 2016, 59, 165-172. [CrossRef]

28. Ko, H.; Cho, C.-H.; Roberts, M.S. Internet uses and gratifications: A structural equation model of interactive advertising. J. Advert. 2005, 34, 57-70. [CrossRef]

29. Ducoffe, R.H. Advertising value and advertising on the web. J. Advert. Res. 1996, 36, 21.

30. Logan, K.; Bright, L.F.; Gangadharbatla, H. Facebook versus television: Advertising value perceptions among females. J. Res. Interact. Mark. 2012, 6, 278-279. [CrossRef]

31. Mehta, A. Advertising attitudes and advertising effectiveness. J. Advert. Res. 2000, 40, 67-72. [CrossRef]

32. McCracken, G. Who is the celebrity endorser? Cultural foundations of the endorsement process. J. Consum. Res. 1989, 16, 310-321. [CrossRef]

33. McGuire, W.J. Attitudes and attitude change. In The Handbook of Social Psychology; Random House: New York, NY, USA, 1985; pp. 233-346.

34. Kiecker, P.; Cowles, D. Interpersonal communication and personal influence on the Internet: A framework for examining online word-of-mouth. J. Euromarketing 2002, 11, 71-88. [CrossRef]

35. Sanders, T. The Likeability Factor: How to Boost Your L-Factor and Achieve Your Life's Dreams; Crown Business: New York, NY, USA, 2006.

36. Fleck, N.; Korchia, M.; Le Roy, I. Celebrities in advertising: Looking for congruence or likability? Psychol. Mark. 2012, 29, 651-662. [CrossRef]

37. Chekima, B.; Chekima, F.Z.; Adis, A.-A.A. Social Media Influencer in Advertising: The Role of Attractiveness, Expertise and Trustworthiness. J. Econ. Bus. 2020, 3, 1507-1515. [CrossRef]

38. Amos, C.; Holmes, G.; Strutton, D. Exploring the relationship between celebrity endorser effects and advertising effectiveness: A quantitative synthesis of effect size. Int. J. Advert. 2008, 27, 209-234. [CrossRef] 
39. Zakay, D. The temporal-relevance temporal-uncertainty model of prospective duration judgment. Conscious. Cogn. 2015, 38, 182-190. [CrossRef]

40. Moreland, R.L.; Zajonc, R.B. Exposure effects in person perception: Familiarity, similarity, and attraction. J. Exp. Soc. Psychol. 1982, 18, 395-415. [CrossRef]

41. Back, M.D.; Schmukle, S.C.; Egloff, B. Becoming friends by chance. Psychol. Sci. 2008, 19, 439. [CrossRef]

42. Wadhera, R. Celebrities and Social Cause-An insight on Review of Literature. Int. J. Res. Publ. 2020, 45, 1-25.

43. Hsu, C.-L.; Lin, J.C.-C. Acceptance of blog usage: The roles of technology acceptance, social influence and knowledge sharing motivation. Inf. Manag. 2008, 45, 65-74. [CrossRef]

44. Kim, M.J.; Chung, N.; Lee, C.-K.; Preis, M.W. Why do smartphone shoppers help others on websites? The effects of attachments on reciprocal altruism. Inf. Dev. 2016, 32, 920-936. [CrossRef]

45. Thomson, M.; Johnson, A.R. Marketplace and personal space: Investigating the differential effects of attachment style across relationship contexts. Psychol. Mark. 2006, 23, 711-726. [CrossRef]

46. White, K.; Peloza, J. Self-benefit versus other-benefit marketing appeals: Their effectiveness in generating charitable support. J. Mark. 2009, 73, 109-124. [CrossRef]

47. Cropanzano, R.; Mitchell, M.S. Social exchange theory: An interdisciplinary review. J. Manag. 2005, 31, 874-900. [CrossRef]

48. Bakshi, S.; Gupta, D.R.; Gupta, A. Online travel review posting intentions: A social exchange theory perspective. Leis. Loisir 2021, 9, 1-31.

49. Frenzen, J.; Nakamoto, K. Structure, cooperation, and the flow of market information. J. Consum. Res. 1993, 20, 360-375. [CrossRef]

50. Blau, P.M. Exchange and Power in Social Life; Routledge: New York, NY, USA, 2017.

51. Shiau, W.-L.; Chau, P.Y. Does altruism matter on online group buying? Perspectives from egotistic and altruistic motivation. Inf. Technol. People 2015, 28, 677-698. [CrossRef]

52. Chiang, H.-S.; Hsiao, K.-L. YouTube stickiness: The needs, personal, and environmental perspective. Internet Res. 2015, $25,85-106$. [CrossRef]

53. Groth, M.; Gilliland, S.W. Having to wait for service: Customer reactions to delays in service delivery. Appl. Psychol. 2006, 55, 107-129. [CrossRef]

54. Chen, C.-J.; Hung, S.-W. To give or to receive? Factors influencing members' knowledge sharing and community promotion in professional virtual communities. Inf. Manag. 2010, 47, 226-236. [CrossRef]

55. van de Ven, A.H. Engaged Scholarship: A Guide for Organizational and Social Research; Oxford University Press: Evans Road Cary, NC, USA, 2007.

56. Shiau, W.-L.; Yuan, Y.; Pu, X.; Ray, S.; Chen, C.C. Understanding fintech continuance: Perspectives from self-efficacy and ECT-IS theories. Ind. Manag. Data Syst. 2020, 120, 1659-1689. [CrossRef]

57. Fritz, N.K. Claim recall and irritation in television commercials: An advertising effectiveness study. J. Acad. Mark. Sci. 1979, 7, 1-13. [CrossRef]

58. Choi, S.M.; Rifon, N.J. It is a match: The impact of congruence between celebrity image and consumer ideal self on endorsement effectiveness. Psychol. Mark. 2012, 29, 639-650. [CrossRef]

59. Teng, S.; Khong, K.W.; Goh, W.W.; Chong, A.Y.L. Examining the antecedents of persuasive eWOM messages in social media. Online Inf. Rev. 2014, 38, 746-768. [CrossRef]

60. Wangenheim, F.V.; Bayón, T. The effect of word of mouth on services switching: Measurement and moderating variables. Eur. J. Mark. 2004, 38, 1173-1185. [CrossRef]

61. Hair, J.F., Jr.; Hult, G.T.M.; Ringle, C.M.; Sarstedt, M. A Primer on Partial Least Squares Structural Equation Modeling (PLS-SEM); Sage Publications: Los Angeles, CA, USA, 2021.

62. Podsakoff, P.M.; MacKenzie, S.B.; Lee, J.-Y.; Podsakoff, N.P. Common method biases in behavioral research: A critical review of the literature and recommended remedies. J. Appl. Psychol. 2003, 88, 879. [CrossRef] [PubMed]

63. Chin, W.W.; Thatcher, J.B.; Wright, R.T.; Steel, D. Controlling for common method variance in PLS analysis: The measured latent marker variable approach. In New Perspectives in Partial Least Squares and Related Methods; Springer-Verlag: New York, NY, USA, 2013; pp. 231-239.

64. Sun, H. Understanding user revisions when using information system features: Adaptive system use and triggers. MIS Q. 2012, 36, 453-478. [CrossRef]

65. Google, T.W. Why People Turn to YouTube. Available online: https://www.thinkwithgoogle.com/data/why-people-turn-toyoutube/ (accessed on 12 July 2021).

66. Lee, J.; Kim, M.; Ham, C.-D.; Kim, S. Do you want me to watch this ad on social media?: The effects of norms on online video ad watching. J. Mark. Commun. 2017, 23, 456-472. [CrossRef] 